\title{
In Vitro Activity of Omadacycline against Chlamydia pneumoniae
}

\author{
Stephan A. Kohlhoff, ${ }^{a}$ Natalia Huerta, ${ }^{a}$ Margaret R. Hammerschlag ${ }^{a}$ \\ aDepartment of Pediatrics, Division of Pediatric Infectious Diseases, State University of New York Downstate Medical Center, Brooklyn, New York, USA
}

ABSTRACT The in vitro activities of omadacycline, azithromycin, doxycycline, moxifloxacin, and levofloxacin were tested against 15 isolates of Chlamydia pneumoniae. The minimum inhibitory concentration at which $90 \%$ of the isolates of C. pneumoniae were inhibited by omadacycline was $0.25 \mu \mathrm{g} / \mathrm{ml}$ (range, 0.03 to $0.5 \mu \mathrm{g} / \mathrm{ml}$ ).

KEYWORDS Chlamydia pneumoniae, omadacycline, tetracyclines

-hlamydia pneumoniae is a frequent cause of community-acquired respiratory infections, including pneumonia and bronchitis, in adults and children (1). Antibiotics commonly used to treat $C$. pneumoniae respiratory infections include macrolides, quinolones, and tetracyclines, specifically doxycycline (2).

Omadacycline (PTK 0796) is a new aminomethylcycline with potent in vitro antibacterial activity against a broad range of bacteria that cause respiratory infections, including Streptococcus pneumoniae (3) and Mycoplasma pneumoniae (4). We compared the in vitro activity of omadacycline with those of azithromycin, doxycycline, moxifloxacin, and levofloxacin against 15 isolates of C. pneumoniae.

Tested isolates of $C$. pneumoniae included 2 isolates from ATCC (Manassas, VA), i.e., TW-183 (VR-2282) and CM-1 (VR-1360), and 13 human isolates from patients with community-acquired pneumonia, including bronchoalveolar lavage specimens from patients with pneumonia from the United States. Omadacycline, azithromycin, levofloxacin, moxifloxacin, and doxycycline were provided as powders and solubilized according to the manufacturers' instructions. Sterile stock solutions of $1,280 \mu \mathrm{g} / \mathrm{ml}$ were made and frozen at $-80^{\circ} \mathrm{C}$. Aliquots of the stock drug suspensions were diluted each time the assay was run. C. pneumoniae isolates were expanded to concentrations of $10^{7}$ to $10^{8}$ inclusion-forming units (IFU) per milliliter by serial passage in tissue culture with antibiotic-free medium as previously described (5). Isolates were purified by centrifugation at $500 \mathrm{rpm}$ to bring down the cell debris. The chlamydia-containing supernatant was pelleted at $17,000 \times g$ for $1 \mathrm{~h}$. The pellet containing the chlamydia was then resuspended in sucrose phosphate glutamate (SPG) and centrifuged through a discontinuous renografin gradient. The chlamydial elementary body (EB)-containing band was then washed 3 times and resuspended in SPG. The titers of the EB suspension were determined in HEp-2 cells (ATCC CCL-23).

Susceptibility testing of $C$. pneumoniae isolates was performed in cell culture by using HEp-2 cells grown in 96-well microtiter plates as previously described (6). Each well was inoculated with $0.2 \mathrm{ml}$ of the test strain diluted to yield $10^{4} \mathrm{IFU} / \mathrm{ml}$; the plates were centrifuged at $1,700 \times g$ for $1 \mathrm{~h}$ and incubated at $35^{\circ} \mathrm{C}$ for $1 \mathrm{~h}$. Wells were then aspirated and overlaid with medium containing $1 \mu \mathrm{g} / \mathrm{ml}$ of cycloheximide and serial 2-fold dilutions of the test drugs. After incubation at $35^{\circ} \mathrm{C}$ for $72 \mathrm{~h}$, cultures were fixed and stained for inclusions with fluorescein-conjugated antibody to the chlamydial lipopolysaccharide genus-specific antigen (Pathfinder Chlamydia Culture Confirmation System; Bio-Rad, Hercules, CA). The MIC was the lowest antibiotic concentration at which no inclusions were seen. The minimal bactericidal concentration (MBC) was
Citation Kohlhoff SA, Huerta N, Hammerschlag MR. 2019. In vitro activity of omadacycline against Chlamydia pneumoniae. Antimicrob Agents Chemother 63:e01907-18. https://doi .org/10.1128/AAC.01907-18.

Copyright $\odot 2019$ American Society for Microbiology. All Rights Reserved. Address correspondence to Stephan A. Kohlhoff, stephan.kohlhoff@downstate.edu. Received 5 September 2018 Returned for modification 1 October 2018 Accepted 25 November 2018

Accepted manuscript posted online 3 December 2018

Published 29 January 2019 
TABLE 1 Activities of omadacycline and comparators against 15 isolates of $C$. pneumoniae

\begin{tabular}{lllllll}
\hline & \multicolumn{2}{l}{ MICs $(\mathrm{mg} / \mathrm{ml})$} & & & \multicolumn{2}{l}{ MBCs $(\mathrm{mg} / \mathrm{ml})$} \\
\cline { 2 - 3 } Drug & Range & MIC $_{50}$ & MIC $_{\mathbf{9 0}}$ & & Range & MBC $_{\mathbf{9 0}}$ \\
\hline Omadacycline & $0.03-0.5$ & 0.06 & 0.25 & & $0.06-0.5$ & 0.5 \\
Azithromycin & $0.03-0.06$ & 0.06 & 0.06 & & $0.06-0.25$ & 0.25 \\
Levofloxacin & $0.25-0.5$ & 0.5 & 0.5 & & $0.25-2$ & 2 \\
Moxifloxacin & $0.25-1.0$ & 0.5 & 1.0 & & $0.5-1.0$ & 1.0 \\
Doxycycline & $0.06-0.25$ & 0.125 & 0.125 & & $0.25-0.5$ & 0.5 \\
\hline
\end{tabular}

determined by aspirating the antibiotic-containing medium, washing wells twice with phosphate-buffered saline, and adding antibiotic-free medium. The infected cells were frozen at $-70^{\circ} \mathrm{C}$, thawed, passed onto new cells, incubated for $72 \mathrm{~h}$, and then fixed and stained as described above. The MBC was the lowest antibiotic concentration that resulted in no inclusions after passage. All tests were run in duplicate. Positive (infection \pm equal volumes drug carrier without active drug added) and negative (addition of medium \pm active drug, not containing any bacteria) infection controls were included with each experiment.

The MICs and MBCs for $C$. pneumoniae are shown in Table 1. The $\mathrm{MIC}_{90}$ of $C$. pneumoniae isolates to omadacycline was $0.25 \mu \mathrm{g} / \mathrm{ml}$ (range, 0.03 to $0.5 \mu \mathrm{g} / \mathrm{ml}$ ). The $\mathrm{MBC}_{90}$ of the isolates to omadacycline was $0.5 \mu \mathrm{g} / \mathrm{ml}$ (range, 0.6 to $0.5 \mu \mathrm{g} / \mathrm{ml}$ ).

The in vitro activity of omadacycline against $C$. pneumoniae infection was comparable with the other antibacterial drugs tested, including doxycycline. The $\mathrm{MIC}_{90}$ and $\mathrm{MBC}_{90}$ were within 2 dilutions of the other agents. However, in vitro activity may not necessarily predict microbiological efficacy in vivo against $C$. pneumoniae infection (2).

The in vitro activity of omadacycline is comparable to those of several antibiotics with proven clinical efficacy. The results presented in this report therefore suggest that omadacycline would be effective for the treatment of infections due to $C$. pneumoniae isolates, depending on the concentrations achieved at the site of infection. Omadacycline has been demonstrated to achieve high, sustained concentrations in plasma, epithelial lining fluid, and alveolar cells, suggesting that it may be effective in the treatment of pulmonary infections, including those caused by intracellular organisms such as C. pneumoniae (7). A recent phase 3 trial found that a single daily dose of omadacycline was noninferior to moxifloxacin for treatment of community-acquired pneumonia caused by C. pneumoniae, based on clinical response (8).

\section{ACKNOWLEDGMENTS}

This study was supported in part by a grant from Paratek Pharmaceuticals, Inc. The funders had no role in study design, data collection, and interpretation or the decision to submit the work for publication.

\section{REFERENCES}

1. Hammerschlag MR, Kohlhoff SA, Gaydos CA. 2014. Chlamydia pneumoniae, p 2174-2182. In Mandell GL, Bennett JE, Dolin R (ed), Principles and Practice of Infectious Diseases, 8th ed. Elsevier, Inc., Philadelphia, PA.

2. Kohlhoff SA, Hammerschlag MR. 2015. Treatment of chlamydial infections: 2014 update. Expert Opin Pharmacother 16:205-212. https:// doi.org/10.1517/14656566.2015.999041.

3. Pfaller MA, Rhomberg PR, Huband MD, Flamm RK. 2018. Activity of omadacycline tested against Streptococcus pneumoniae from a global surveillance program. Diagn Microbiol Infect Dis 90:143-147. https://doi .org/10.1016/j.diagmicrobio.2017.10.010.

4. Waites KB, Crabb DM, Lui Y, Duffy LB. 2016. In vitro activities of omadacycline (PTK 0796) and other antimicrobial agents against human mycoplasmas and ureaplasmas. Antimicrob Agents Chemother 60:7502-7504. https://doi.org/10.1128/AAC.01734-16.

5. Kohlhoff SA, Huband MD, Hammerschlag MR. 2014. In vitro activity of AZD0914, a novel DNA gyrase inhibitor, against Chlamydia trachomatis and Chlamydia pneumoniae. Antimicrob Agents Chemother 58: 7595-7596. https://doi.org/10.1128/AAC.03920-14.

6. Roblin PM, Dumornay W, Hammerschlag MR. 1992. Use of HEp-2 cells for improved isolation and passage of Chlamydia pneumoniae. J Clin Microbiol 30:1968-1971.

7. Gotfried MH, Horn K, Garrity-Ryan L, Villano S, Tzanis E, Chitra S, Manley TSK, Rodvold KA. 2018. Comparison of omadacycline and tigecycline pharmacokinetics in the plasma, epithelial lining fluid, and alveolar cells of healthy adults. Antimicrob Agents Chemother 61:e01135-17. https:// doi.org/10.1128/AAC.01135-17.

8. Stets R, Popescu M, Gonong J, Mitha I, Nseir W, Madej A, Kirsch C, Das A Garrity-Ryan L, Steenbergen JN, Manley A, Eckburg PB, Villano S, Tzanis E, McGovern P, Loh E. 2017. A phase 3, randomized, double-blind, multicenter study to compare the safety and efficacy of IV to oral omadacycline to moxifloxacin for the treatment of adult patients with CABP (the OPTIC study). Open Forum Infect Dis 4(Suppl 1):S543. https://doi.org/10.1093/ ofid/ofx163.1413. 